\title{
Electroencephalographic study of divers with histories of neurological decompression illness
}

\author{
A W Murrison, E Glasspool, R J Pethybridge, T J R Francis, E M Sedgwick
}

\begin{abstract}
Objective-To determine whether divers with histories of neurological decompression illness are electroencephalographically distinguishable from non-divers. Methods-The electroencephalograms (EEGs) from 68 divers with histories of neurological decompression illness and 45 non-diver controls were examined independently by two clinical neurophysiologists.

Results-The diver and non-diver groups were electroencephalographically indistinguishable.

Conclusion-There is no electroencephalographic evidence for the existence of cerebral dysfunction in divers with histories of decompression illness.
\end{abstract}

(Occup Environ Med 1995;52:451-453)

Keywords: electroencephalography; diver; decompression

Acute neurological decompression illness is well described among divers, compressed air workers, and aviators. It has been suggested that the brain is commonly involved in dysbaric illness and that diving may cause insidious neurological deterioration. The most compelling evidence for this consists of the diffuse cerebral white matter vasculopathy and lacuna formation shown at postmortem examination by Palmer et al. ${ }^{1}$ A process of vascular obstruction was further suggested by the description of retinal vascular abnormalities, pigment epithelial changes, and a reduction in macula capillary density in divers. ${ }^{2}$ An indication that these structural changes might have a functional significance has been shown by psychometric abnormalities in divers. ${ }^{34}$

The electroencephalogram (EEG) is well established as a means of detecting changes, which are mainly non-specific, in a broad spectrum of focal and generalised cerebral disease processes. Subclinical cerebral dysfunction as a result of occupational exposure to several noxious substances ${ }^{5}$ has been shown by EEGs, and this usually takes the form of diffuse slow wave changes.

The studies of EEGs to detect possible neurological changes in hyperbaric workers have been reviewed by Murrison. ${ }^{6}$ Rozsahegyi and Roth's uncontrolled study ${ }^{7}$ reported abnormal EEGs in $67 \%$ of 57 caisson workers with a recent or remote history of neurological decompression illness compared with $25 \%$ of caisson workers without histories of decompression illness and an estimated $20 \%$ of the general population. This suggested a high prevalence of cerebral involvement in human decompression illness and predated similar observations by Leitch and Hallenbeck ${ }^{8}$ in a dog model of the disease.

Kwiatkowski ${ }^{9}$ found that $43 \%$ of 150 professional air divers possessed abnormal EEGs compared with $33 \%$ of 78 non-divers. The study of Dolmierski et $a l^{10}$ found that 60 $(40 \%)$ of 150 professional air divers had abnormalities of their EEGs compared with five $(10 \%)$ of 50 poorly defined non-diver controls. In a more rigorous study, Todnem et $a l^{11}$ reported a highly significant difference in the number of abnormal EEGs among 150 commercial air and saturation divers (18\%) compared with a non-diver control group of 100 (5\%) "offshore personnel" and policemen. The occurrence of abnormalities, which consisted mainly of slow wave changes and sharp potentials, correlated highly with exposure to both forms of diving and with histories of decompression illness ( 51 of the 150 divers had experienced neurological decompression illness). Todnem $e t a l^{11}$ pointed out that similar changes in EEGs had been noted both experimentally ${ }^{12}$ and clinically ${ }^{13}$ after the introduction of gas to the cerebral circulation and consequently suggested that their findings might be indicative of cerebral ischaemic changes generated by gas bubbles. In contrast, Malhotra and Kumar's investigation, ${ }^{14}$ which was performed without the benefit of control data, found a lower prevalence of abnormal EEGs among 98 Indian naval divers than had been reported in general populations ${ }^{15}$. This might be anticipated from the "healthy worker effect" described by Hernberg ${ }^{16}$. Another small and uncontrolled study was performed by Hjorth et al with Australian abalone divers ${ }^{17}$ as subjects. Despite the fact that these divers are distinguished by their habitual exposure to excessive decompression stress, only two abnormal EEGs and one borderline EEG were recorded from the 20 divers studied.

\section{Subjects and methods}

Potential subjects who had been treated for neurological decompression illness between one month and four years previously (mean 17 months) were identified from the records of the Institute of Naval Medicine, Alverstoke, the Diving Diseases Research Centre, Plymouth, and Whipps Cross Hospital, London. ${ }^{18}$ Four cases were referred 
by Health and Safety Executive approved physicians with experience of divers. Two patients in whom the diagnosis of decompression illness was questionable were excluded. ${ }^{19}$ Four potential participants with histories of either neurological disease other than decompression illness, head injury with loss of consciousness, current or past alcohol misuse, or other serious systemic illness were also excluded. The EEGs were acquired from 68 divers. Forty five non-diver controls were drawn from a wide spectrum of workers at the Institute of Naval Medicine, Southampton General Hospital, the Diving Diseases Research Centre, and auxiliary coastguard services. Standards for entry into the study were the same for divers and non-divers. The mean age (range) of the divers was 35 (20-62) and of the non-divers was 32 (16-59).

The clinical status of the divers was determined from their medical history and neurological examination, which was performed by a single physician (AWM). Thirty nine of the 68 divers complained of or were found to have residual symptoms or signs. These were further broken down into divers with "hard" and divers with "soft" features. ${ }^{18}$ For example, the demonstration of definite motor weakness or a convincing area of numbness would be regarded as a hard finding, whereas a diver's report that the sensation of pin prick was altered but in whom an objective deficit could not be shown would be classified as a soft feature. Of those with residua, 15 had features indicative of cerebral involvement. These were invariably of an equivocal or minor nature, typically the impression of occasional forgetfulness or lapses in concentration,

Table 1 Number of normal, equivocal, and abnormal EEGs in divers and controls according to assessors $A$ and $B$

\begin{tabular}{|c|c|c|c|c|c|c|}
\hline \multirow[b]{2}{*}{ Assessor } & \multicolumn{2}{|c|}{ Normal } & \multicolumn{2}{|c|}{ Equivocal } & \multicolumn{2}{|c|}{ Abnormal } \\
\hline & $A$ & $B$ & $A$ & $B$ & $A$ & $B$ \\
\hline $\begin{array}{l}\text { Divers } \\
\text { Controls } \\
\text { Total }\end{array}$ & $\begin{array}{l}40 \\
24 \\
64\end{array}$ & $\begin{array}{l}38 \\
21 \\
59\end{array}$ & $\begin{array}{r}17 \\
7 \\
24\end{array}$ & $\begin{array}{r}20 \\
9 \\
29\end{array}$ & $\begin{array}{l}11 \\
14 \\
25\end{array}$ & $\begin{array}{l}10 \\
15 \\
25\end{array}$ \\
\hline
\end{tabular}

Table 2 Assessors' worse assessment of EEG $v$ presence or absence of all forms of neurological residua in divers and controls

\begin{tabular}{llllll}
\hline & \multicolumn{5}{l}{ Residua } \\
\cline { 2 - 6 } & \multicolumn{5}{c}{ Divers } \\
\cline { 2 - 6 } Assessment & Non-divers & None & Soft & Hard & All \\
& $n(\%)$ & $n(\%)$ & $n(\%)$ & $n(\%)$ & $n(\%)$ \\
\hline Normal & $18(40)$ & $15(52)$ & $10(38)$ & $6(46)$ & $31(46)$ \\
Equivocal & $8(18)$ & $4(14)$ & $10(38)$ & $6(46)$ & $20(29)$ \\
Abnormal & $19(42)$ & $10(34)$ & $6(23)$ & $1(8)$ & $17(25)$ \\
Total & $45(100)$ & $29(100)$ & $26(100)$ & $13(100)$ & $68(100)$ \\
\hline
\end{tabular}

Table 3 Worse assessment of EEG $v$ presence or absence of higher function residua

\begin{tabular}{llllll}
\hline & \multicolumn{5}{c}{ Residua } \\
\cline { 2 - 6 } & \multicolumn{5}{c}{ Divers } \\
\cline { 3 - 6 } Assessment & Non-divers & None & Soft & Hard & All \\
\hline Normal & $n(\%)$ & $n(\%)$ & $n(\%)$ & $n(\%)$ & $n(\%)$ \\
Equivocal & $18(40)$ & $26(49)$ & $5(36)$ & $0(0)$ & $31(46)$ \\
Abnormal & $8(18)$ & $14(26)$ & $5(36)$ & $1(100)$ & $20(29)$ \\
Total & $19(42)$ & $13(25)$ & $4(29)$ & $0(0)$ & $17(25)$ \\
& $45(100)$ & $53(100)$ & $14(100)$ & $1(100)$ & $68(100)$ \\
\hline
\end{tabular}

apart from those in a single diver whose performance on "serial 7" and proverb interpretation was abnormal. All of the non-divers were normal.

Informed consent was obtained from volunteers and the investigation was approved by the ethics committee of both Southampton General Hospital and the Royal Navy.

Sixteen channel EEGs were recorded on volunteers in a single laboratory with the Micromed Brainquick apparatus with electrodes arranged according to the 10-20 system. Volunteers were awake but relaxed and reclined in the supine position. A five minute recording was taken during which the eyes were shut apart from two 10 second periods when volunteers were asked to open their eyes. Recording continued during a further three minutes of hyperventilation followed by two minutes at rest.

Two consultant clinical neurophysiologists from Wessex Regional Health Authority were asked to interpret the EEGs as normal, equivocal, or abnormal in accordance with criteria in general clinical use at the Wessex Neurological Centre. Thus, the presence of spikes and sharp waves, clearly excessive quantities of slow wave activity, and notable rhythm asymmetry were determinants of abnormality. Assessments were made independently and the assessors were ignorant of subject status.

\section{Results}

Table 1 shows the interpretations of the two assessors. Based on the worse diagnostic assessment of the two in each case, the diagnostic distributions for non-divers and divers were not significantly different $\left(\chi^{2}=4.20 ; 2\right.$ degrees of freedom, $\mathrm{P}>0 \cdot 1)$. Within the diver group there was no association between assessment on EEG and either the number of dives made or time since the accident. Tables 2 and 3 provide a summary of the worse assessment of EEGs against the presence of hard and soft neurological residua and, specifically, the presence of higher function residua. No link between residua and diagnosis on the EEGs could be established.

\section{Discussion}

The generally positive association between abnormality on EEG and hyperbaric exposure that emerged from previous electroencephalographic studies of divers and caisson workers $^{791011}$ was not replicated in this study. The absence of abnormalities of EEGs in divers with histories of neurological decompression illness does not support the contention that diving is responsible for subclinical damage to the nervous tissue of divers. Furthermore, no evidence was found through EEGs to support the suggestion that the brain is often involved in what has traditionally been regarded as a spinal cord disease.

The negative findings submitted concur with the authors' account of an overlapping population of divers with histories of neurological decompression illness in which 
somatosensory evoked responses to posterior tibial and median nerve stimulation were compared with those of non-divers. No evidence was given for the presence of subclinical damage to the neuraxis. ${ }^{18}$

Notwithstanding the ability of EEGs to detect subclinical changes in a wide variety of pathological processes, it is possible that the technique may be insufficiently sensitive to detect the more subtle of the cumulative cerebral changes that might occur in divers.

The study was funded by the Department of Energy and was supported by the Medical Director General (Naval). The assistance of Surgeon Commander $\mathrm{J} J$ W Sykes, Dr M R Cross, Dr M R Hamilton-Farrell, Dr J D Cole, and Dr L Merton is gratefully acknowledged.

1 Palmer AC, Calder IM, Yates PO. Cerebral vasculopathy in divers. Neuropathol Appl Neurobiol 1992;18:113-24.

in divers. Neuropathol Appl Neurobiol 1992;18:113-24.
Polkinghorne PJ, Cross MR, Sehmi K, Minassian D, Bird Polkinghorne PJ, Cross MR, Sehmi K, Minassian D, Bird AC. Oc

3 Peters BH, Levin HS, Kelly PJ. Neurological and psychologic manifestations of decompression illness in divers. Neurology 1977;27:125-7.

4 Leach J, King J, Morris PE, Rawlins J. Memory and personality changes of caisson workers with a history of decompression illness. In: Engineering and health in compressed air workers. Proceedings of a conference. Cambridge: CIRIA, 1992.

5 Seppalainen AM, Lindstrom K, Martelin T. Neurophysiological and psychological picture of solvent

poisoning. Am f Ind Med 1980;1:31-42.
6 Murrison AW. The contribution of neurophysiological techniques to the investigation of diving-related illness. Undersea Hyperb Med 1993;20:347-3.
7 Rozsahegyi I, Roth B. Participation of the central nervous system in decompression. Industrial Medicine and Surgery 1966;35:101-8.

8 Leitch DR, Hallenbeck JM. A model of spinal cord dysbarism to study delayed treatment: II effects of treatment. Aviat Space Environ Med 1985;55:679-84.

9 Kwiatkowski SR. Analysis of EEG records among divers. Bulletin of the Institute of Medicine (Morsk) 1979;2:131-5.

10 Dolmierski R, Kwiatkowski SR, Nitka J, Palubicki J, Laba L. Neurological, psychiatric and psychological examinations of divers in the light of their professional work. Bull tionst Mar Trop Med Gdymia 1981;32:141-52.

11 Todnem K, Skeidsvoll H, Svihus R, Rinck P, Riise T, Kambestad BK, Aarli JA. Electroencephalography, evoked potentials and MRI brain scans in saturation divers. An epidemiological study. Electroencephalogr Clin Neurophysiol 1991;79:322-9.

12 Fritz H, Hossmann KA. Arterial air embolism in cat brain. Stroke 1979;10:581-9.

13 Ingvar D H, The pathophysiology of occlusive cerebrovascular disorders related to neuroradiological findings, EEG, and measurements of regional cerebral blood flow. Acta Neurol Scand 1967;43:93-107.

14 Malhotra MS, Kumar CM. Electroencephalography in naval divers. Aviat Space Environ Med 1975;46:1000-1.

15 Cobb WA. The normal adult EEG. In: Hill D, Parr G, eds. Electroencephalography. New York: MacMillan 1963; 232-49.

16 Hernberg S. Epidemiology in occupational health. In: Zenz C ed. Occupational medicine. Principles and practical applications 2nd ed. Chicago: Year Book Medical Publishers 1988;1132-3.

17 Hjorth R, Edmonds C, Vignaendra V. Electroencephalographic and evoked cortical potentials assessments in divers. In: Edmonds C, ed. Abalone Diver. National Safety Council of Australia 1986; 115-30.

18 Murrison AW, Glasspool E, Pethybridge RJ, Francis TJR, Sedgwick EM. Neurophysiological assessment of divers with histories of neurological decompression illness. Occup Environ Med 1994;51:730-4.

19 Elliott DH, Moon RE. Manifestations of the decompression disorders. In: Bennett $\mathrm{PB}$, Elliott $\mathrm{DH}$, eds. The physiology and medicine of diving, 4th ed. London: W B physiology and medi

\section{Instructions to authors}

Three copies of all submissions should be sent to: The Editor, Occupational and Environmental Medicine, BMJ Publishing Group, BMA House, Tavistock Square, London WC1H 9JR, UK. All authors should sign the covering letter as evidence of consent to publication. Papers reporting results of studies on human subjects must be accompanied by a statement that the subjects gave written, informed consent and by evidence of approval from the appropriate ethics committee. These papers should conform to the principles outlined in the Declaration of Helsinki (BMF 1964;ii:177).
If requested, authors shall produce the data on which the manuscript is based, for examination by the Editor.

Authors are asked to submit with their manuscript the names and addresses of three people who they consider would be suitable independent reviewers. They will not necessarily be approached to review the paper.

Papers should include a structured abstract of not more than 300 words, under headings of Objectives, Methods, Results, and Conclusions. Please include up to three keywords or key terms to assist with indexing. 